\title{
Anthelmintic Macrolactams from Nonomuraea turkmeniaca MA7381
}

\author{
Sloan Ayers, Deborah L. Zink, Joanne Staats Powell, Christine M. Brown, Alan Grund, \\ Olga Genilloud, Oscar Salazar, Donald Thompson, Sheo B. Singh
}

Received: November 16, 2007 / Accepted: January 18, 2008

(C) Japan Antibiotics Research Association

\begin{abstract}
A new macrolactam, fluvirucin $\mathrm{B}_{0}(\mathbf{1})$, and two known macrolactams, Sch 38516/fluvirucin $B_{1}(2)$ and Sch 39185/fluvirucin $\mathrm{B}_{3}(\mathbf{3})$, have been isolated from an acetone extract of a strain of Nonomuraea turkmeniaca. These compounds were isolated by bioassay-guided fractionation as part of our search for new anthelmintics. The structures of these compounds were elucidated by comparison of their NMR and MS data to those of previously reported fluvirucins, and confirmed by 2D-NMR. 1 $\sim 3$ exhibited in vitro activity $\left(\mathrm{EC}_{90}<1.0 \sim 1.7 \mu \mathrm{g} / \mathrm{ml}\right)$ against Haemonchus contortus larvae, but were ineffective in reducing worm counts in vivo against Heligmosomoides polygyrus in mice at $50 \mathrm{mg} / \mathrm{kg}$ dosed intramuscularly.
\end{abstract}

Keywords macrocyclic lactone, fluvirucins, anthelmintic, Nonomuraea species, Natural product isolation and structure elucidation

\section{Introduction}

Productivity to the sheep and goat industry has been significantly compromised by infections caused by internal parasites (e.g., Haemonchus contortus). A number of new classes of anthelmintic drugs have been approved for clinical use since 1960 including the current classes of synthetic drugs such as the benzimidazoles and imidazothiazoles (tetramisole/levamisole). The discovery of the avermectin class of macrolactones in the early 1980's, however, represented the most significant of discoveries not only as anthelmintic agents for animal health, but also for treatment of parasitic infections to humans, particularly onchocerciasis (river blindness). This discovery led to the anthelmintic drugs ivermectin and doramectin, which have excellent broad-spectrum activity and superior potency. Unfortunately, resistance to all classes of drugs has been observed, leading to the continuing need for further research to discover new classes of anthelmintics, particularly those with novel modes of action [1].

To discover anthelmintic agents, our strategy has been to screen extracts of bacterial and fungal fermentations as well as plants for in vitro activity against $H$. contortus [2], a prevalent parasitic worm species that infects small ruminants. In vivo activity was evaluated using

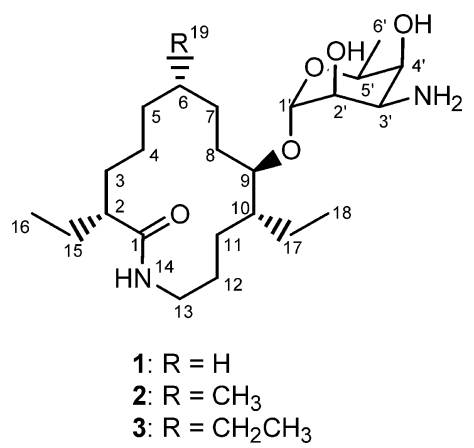

S. B. Singh (Corresponding author), S. Ayers, D. L. Zink: Natural Products Chemistry, Merck Research Laboratories, P.O. Box 2000, Rahway, NJ 07065, E-mail: sheo_singh@merck.com J. S. Powell, C. M. Brown, D. Thompson: Merck and Co., Inc., Branchburg Farm, 203 River Road, Somerville, NJ 08876
A. Grund: Bio-Technical Resources, 1035 South 7th St., Manitowoc, WI 54220

O. Genilloud, O. Salazar: Centro de Investigación Básica, Merck, Sharp \& Dohme de Espana, S.A., Josefa Valcarcel 38, 28027 Madrid, Spain 
Heligmosomoides polygyrus infected mice [3]. An acetone extract of an actinomycete strain of Nonomuraea turkmeniaca MA7381 showed in vitro activity and was selected for further study. Bioassay-guided fractionation using the in vitro assay led to the isolation of three macrolactams fluvirucin $\mathrm{B}_{0}(\mathbf{1})$, Sch 38516/fluvirucin $\mathrm{B}_{1}$ (2), Sch 39185/fluvirucin $B_{3}$ (3) of the fluvirucin class. The isolation, structure and biological activities of these compounds are herein described.

The fermentation broth generated from the producing organism MA7381 was extracted with $\mathrm{Me}_{2} \mathrm{CO}$ and successively chromatographed on Amberchrome and RPHPLC affording 11.0, 14.0, and $8.2 \mathrm{mg}$ of $\mathbf{1} \sim \mathbf{3}$, respectively, as white amorphous powders. Fractions from each step of the fractionation were tested for biological activity against in vitro $H$. contortus assay. The presence of the compounds in the active fractions and the homogeneity was monitored throughout the isolation procedure by HPLC-ELSD (evaporative light-scattering detector), due to the very low UV absorbance of these compounds, even at $210 \mathrm{~nm}$.

HRESIFT-MS of $\mathbf{1}$ yielded a molecular formula $\mathrm{C}_{23} \mathrm{H}_{44} \mathrm{~N}_{2} \mathrm{O}_{5}$. The formula indicated an three degrees of unsaturation. The DEPT spectrum indicated the presence of three methyl groups, eleven methylenes, and eight methines. A single quaternary carbon signal was present at $\delta_{\mathrm{C}} 179.0 \mathrm{ppm}$, which indicated a carbonyl group accounting for one degree of unsaturation. The lack of resonances for other $s p^{2}$ carbons in the ${ }^{13} \mathrm{C}$-NMR spectrum suggested that 1 must therefore contain two rings. Features of the ${ }^{1} \mathrm{H}-\mathrm{NMR}$ spectrum include numerous signals between $\delta_{\mathrm{H}} 3.4 \sim 4.0 \mathrm{ppm}$ as well as a doublet at $\delta_{\mathrm{H}} 4.92 \mathrm{ppm}$, consistent with the presence of a sugar residue, which would be a source of one of the two rings. A multiplet present at $\delta_{\mathrm{H}} 8.02 \mathrm{ppm}$ that showed no correlation in the HSQC spectrum was consistent with an amide proton whose exchange rate in $\mathrm{CD}_{3} \mathrm{OD}$ was extremely slow. Many overlapping protons in the $\delta_{\mathrm{H}} 1.1 \sim 1.6 \mathrm{ppm}$ range indicated a high degree of saturation, consistent with the low index of hydrogen deficiency. Two overlapping methyl triplets were present from $\delta_{\mathrm{H}} 0.84 \sim 0.88$, and a methyl doublet was present at $\delta_{\mathrm{H}} 1.24$, which is a typical chemical shift for the methyl group of a 6-deoxy sugar.

Comparison of the data described above with the corresponding literature data resulted in a very close match to a class of macrolactams isolated from the genus Actinomadura [4 10], of which numerous species have been reclassified as Nonomuraea [11]. These compounds contain a branched 14-membered lactam, a mycosamine or 4-epi-mycosamine moiety, and have exhibited antifungal [4 7] and antiviral properties [8]. The branching usually varies from three methyl groups to three ethyl groups, as well as combinations of methyl, ethyl, and hydroxyethyl groups at C-2, C-6, and C-10. The amino sugar moiety is attached to the macrocycle either at C-3 or C-9. It was apparent from the COSY spectra of $\mathbf{1} \sim \mathbf{3}$ that the sugar was attached at C-9 like the fluvirucin "B" series (the proton signal for $\mathrm{H}-2$ did not correlate to any protons adjacent to oxygen). From the small coupling constants of the sugar protons, the sugar component of $\mathbf{1} \sim \mathbf{3}$ was determined to be 4-epi-mycosamine. 1 differed from known fluvirucins in that only three methyl groups were present according to the DEPT spectrum, indicating that instead of three methyl/ethyl branches off of the macrocycle, $\mathbf{1}$ only had two alkyl branches.

2 and 3 showed molecular weights of 442 and 456, respectively, by low-resolution MS. These formulae differ from 1 by incremental mass units of $14\left(\mathrm{CH}_{2}\right)$. The NMR data of 2 and 3 were practically identical to that of Sch $38516 /$ fluvirucin $B_{1}$ and Sch 39185/fluvirucin $B_{3}[4,5]$. The placement of the macrocyclic methyl branch of $\mathbf{2}$ was confirmed by HMBC: the methyl protons showed a doublet at $\delta_{\mathrm{H}} 0.92$ that correlated in the HMBC to three carbon signals at $\delta_{\mathrm{C}} 35.4,32.3$, and 25.8, suggesting the methyl branch could not occur at C-2 because there would be a correlation to the carbonyl at $\delta_{\mathrm{C}} 177 \sim 180$. The methyl branch could also not be placed at $\mathrm{C}-10$, because there would be a correlation to C-9 occurring at $\delta_{\mathrm{C}} 76 \sim 79.3$ contained three ethyl groups at C-2, C-6, and C-10. The assignment of the positions of the ethyl groups for $\mathbf{1}$ was made by $\mathrm{HMBC}$ as well. The $\mathrm{H}_{3}-16$ methyl protons correlated to $\delta_{\mathrm{C}} 51.1(\mathrm{C}-2)$. The $\mathrm{H}_{3}-18$ protons correlated to $\delta_{\mathrm{C}} 42.3$, which was determined to be $\mathrm{C}-10$ by its correlation to H-10 $\left(\delta_{\mathrm{H}} 1.54\right)$ in the HSQC spectrum, which showed a correlation to $\mathrm{H}-9$ ( $\left.\delta_{\mathrm{H}} 3.62\right)$ in the COSY spectrum. Therefore, $\mathbf{1} \sim \mathbf{3}$ differ by the substituent at C-6.

1 $\sim 3$ were first evaluated in the in vitro $H$. contortus assay as described earlier [2]. All three compounds reduced motility of L3 larvae and showed $\mathrm{EC}_{90}$ (effective concentration of compounds that exhibited $90 \%$ reduction of larval motility) of $<1.0,1.5$, and $1.7 \mu \mathrm{g} / \mathrm{ml}$, respectively. 1 and 2 were further evaluated in an in vivo mouse model infected with $H$. polygyrus [3]. Compounds were administered intramuscularly at a dose of $50 \mathrm{mg} / \mathrm{kg}$ in a vehicle containing $60 \%$ propylene glycol and $40 \%$ glycerol $(\mathrm{v} / \mathrm{v})$. Three mice were used for evaluation of each compound and data was averaged. 1 and $\mathbf{2}$ showed no reduction in worm counts compared to negative control. In a similar assay, $N$-methylfluviricin $\mathrm{A}_{1}$ provided modest $(42 \pm 15 \%)$ reduction of worm counts at $50 \mathrm{mg} / \mathrm{kg}$ [12] Ivermectin was used as the positive control in the in vitro assay $\left(\mathrm{EC}_{90} 0.18 \mu \mathrm{g} / \mathrm{ml}\right)$, as well as the in vivo assay $(98 \%$ reduction of larval motility at $10 \mathrm{mg} / \mathrm{kg}$ dosed 
intramuscularly).

In summary, we have reported a new derivative of the fluvirucin B series, as well as the anthelmintic activity of these compounds. 1, along with known $\mathbf{2}$ and $\mathbf{3}$ show in vitro anthelmintic activity, but have no in vivo activity. These classes of compounds are known to be antifungal [4 7] and anti-influenza agents [8]. The current report of anthelmintic activity is a new addition of the biological activity for this class of compounds. Clearly the poor anthelmintic potency prevents them from further development.

\section{Experimental}

\section{Section General Experimental Procedures}

Optical rotation was obtained on a Perkin-Elmer 241 Polarimeter. IR spectral data was obtained on a PerkinElmer Spectrum One spectrometer. NMR spectra were obtained on a Varian Inova $500 \mathrm{MHz}$ spectrometer operating at $500 \mathrm{MHz}$ for ${ }^{1} \mathrm{H}$ and $125 \mathrm{MHz}$ for ${ }^{13} \mathrm{C}$ nuclei in $\mathrm{CD}_{3} \mathrm{OD}$. High-resolution mass spectra were obtained on a Thermo Finnigan LTQ-FT with the standard Ion Max API source (without the sweep cone) and ESI probe. Analysis of fractions was performed with an Agilent 1100 Series HPLC chromatograph with a Polymer Laboratories PL-ELS 2100 evaporative light-scattering detector operated with a nebuliser temperature of $40^{\circ} \mathrm{C}$, an evaporator temperature of $80^{\circ} \mathrm{C}$, and a $\mathrm{N}_{2}$ flow rate of $1.60 \mathrm{SLM}$. Solvents were obtained from Sigma-Aldrich and were used without further purification. Ivermectin was obtained as the commercial product Ivomec Injection (1.0\%) for Cattle and Swine (Merial, Duluth, GA). Swiss Webster mice were obtained from Taconic Labs (Germantown, NY).

\section{Producing Organism and Fermentation}

The organism was obtained from a soil sample collected under a coffee tree in the Jardin de Biodiversidad at INBio, Costa Rica. The strain MA7381 was isolated on soil extract agar medium after pretreatment of the soil with benzethonium chloride.

The organism was grown on agar plates at $28^{\circ} \mathrm{C}$ consisting of yeast extract ( $3.0 \mathrm{~g} /$ liter $)$, malt extract $(10 \mathrm{~g} /$ liter $)$, dextrose ( $4.0 \mathrm{~g} /$ liter $)$, and agar $(20 \mathrm{~g} /$ liter $)$, adjusted to $\mathrm{pH} 7$. Agar plugs were used to inoculate $250-\mathrm{ml}$ baffled flasks containing $50 \mathrm{ml}$ ATCC-2 medium, which consists of soluble starch ( $20 \mathrm{~g} /$ liter $)$, dextrose ( $10 \mathrm{~g} /$ liter $)$, NZ Amine EKC (Kerry) ( $5.0 \mathrm{~g} /$ liter), Difco beef extract ( $3.0 \mathrm{~g} /$ liter), Bacto peptone $(5.0 \mathrm{~g} /$ liter $)$, yeast extract $(5.0 \mathrm{~g} /$ liter $)$, and $\mathrm{CaCO}_{3}$ (1.0 g/liter), adjust to $\mathrm{pH} 7.0$ with $\mathrm{NaOH}$ before addition of $\mathrm{CaCO}_{3}$.
After three days incubation $\left(220 \mathrm{rpm}, 28^{\circ} \mathrm{C}\right)$, these flasks were used to inoculate ( $2.0 \%$ inoculum) 1 -liter production flasks containing $225 \mathrm{ml}$ GOT medium consisting of glycerol $(60 \mathrm{~g} /$ liter $)$, oatmeal $(15 \mathrm{~g} /$ liter $)$, tomato paste $(5.0 \mathrm{~g} /$ liter $)$, and $\mathrm{CaCO}_{3}(3.0 \mathrm{~g} /$ liter $)$, adjusted to $\mathrm{pH} 7.0$. Production flasks were incubated for 13 days $(220 \mathrm{rpm}$, $28^{\circ} \mathrm{C}$ ). Total cultures were harvested and kept at $-20^{\circ} \mathrm{C}$ until thawed for metabolite extraction.

\section{Identification of the Actinomycete Strain}

The actinomycete isolate was identified as another strain of the genus Nonomuraea on the basis of its complete $16 \mathrm{~S}$ rDNA sequence aligned with nucleotide sequences from Genbank. The taxonomic position of the strain was determined by phylogenetic analysis of the aligned 16S rDNA sequences of validated species of the genus Nonomuraea and other members of the family Streptosporangiaceae. From the phylogenetic analysis based on the maximum parsimony method, the strain is an isolate of the type species Nonomuraea turkmeniaca MA7381.

\section{Extraction and Isolation}

Three liters of fermentation broth was mixed with 3.0 liters $\mathrm{Me}_{2} \mathrm{CO}$ and shaken for 1 hour on a platform shaker. The extract was filtered in a sintered-glass funnel using celite as a filter aid. The cells were washed with $500 \mathrm{ml}$ of $\mathrm{MeOH}$ and added to the aq $\mathrm{Me}_{2} \mathrm{CO}$ extract. This extract was concentrated by rotary evaporation to aqueous ( $\sim 2.8$ liters). The concentrate was loaded onto Amberchrome CG 161M ( $\sim 150 \mathrm{ml}$ of resin, column $1^{\prime \prime}$-diameter) at $15 \mathrm{ml} /$ minute. The column was then eluted with a gradient of $\mathrm{MeOH} /$ water at $10 \mathrm{ml} /$ minute $(5.0 \% \mathrm{MeOH}$ for 15 minutes, $5 \sim 100 \% \mathrm{MeOH}$ over 150 minutes, followed by an additional 5 minutes with $100 \% \mathrm{MeOH}$ ). Fractions were collected every five minutes, totaling 34 fractions. The column was further washed with $500 \mathrm{ml}$ of $\mathrm{Me}_{2} \mathrm{CO}$. Fractions from each step of the fractionations were tested for the biological activity using H. controtus in vitro assay. Fractions $27 \sim 34$ were active in the in vitro assay. They were pooled and evaporated to give $605 \mathrm{mg}$ of an off-white powder. A $305 \mathrm{mg}$ portion of this material was dissolved in $4.0 \mathrm{ml}$ of $1: 1 \mathrm{DMSO} /$ $\mathrm{MeOH}$ and filtered. This active material was fractionated in eight $500 \mu 1$ injections by preparative RP-HPLC (Waters Symmetry $\mathrm{C}_{18}, 300 \times 19 \mathrm{~mm}, 7.0 \mu \mathrm{m}, 40$ minutes gradient of $20 \sim 100 \%$ aq $\mathrm{CH}_{3} \mathrm{CN}$ both containing $0.1 \%$ TFA, $10 \mathrm{ml} /$ minute). Fractions were collected every 0.5 minutes. Fractions 30 32 were combined and lyophilized $(11.0 \mathrm{mg}$, $7.3 \mathrm{mg} /$ liter) and contained 1, fractions 33 35 (14.0 mg, $9.3 \mathrm{mg} /$ liter) contained 2 , and fractions $36 \sim 38(8.2 \mathrm{mg}$, $5.4 \mathrm{mg} /$ liter) contained $\mathbf{3}$. 


\section{Fluvirucin $\mathrm{B}_{0}(\mathbf{1})$}

White solid: $[\alpha]_{\mathrm{D}}^{23}-38^{\circ}\left(c 0.5,1: 1 \mathrm{MeOH} / \mathrm{CHCl}_{3}\right)$; IR (ZnSe film) $v_{\max } 3303,2927,1674,1635,1447,1204$, 1140, 1052, $800 \mathrm{~cm}^{-1}$; ${ }^{1} \mathrm{H}-\mathrm{NMR}\left(\mathrm{CD}_{3} \mathrm{OD}, 500 \mathrm{MHz}\right) \delta$ 8.02 (slowly exchanges, dd, $J=7.5,3.0 \mathrm{~Hz}, \mathrm{NH}-14$ ), 4.92 $\left(1 \mathrm{H}, \mathrm{d}, J=1.2 \mathrm{~Hz}, \mathrm{H}-1^{\prime}\right), 4.01(1 \mathrm{H}, \mathrm{qd}, J=6.5,<1 \mathrm{~Hz}, \mathrm{H}-$ $\left.5^{\prime}\right), 3.70\left(1 \mathrm{H}, \mathrm{dd}, J=3.0,1.5 \mathrm{~Hz}, \mathrm{H}-2^{\prime}\right), 3.64(1 \mathrm{H}, \mathrm{dd}$, $\left.J=1.5,<1 \mathrm{~Hz}, \mathrm{H}-4^{\prime}\right), 3.62(1 \mathrm{H}, \mathrm{m}, \mathrm{H}-9), 3.58 \sim 3.52(1 \mathrm{H}$, m, H-13a), $3.47\left(1 \mathrm{H}, \mathrm{t}, J=3.0 \mathrm{~Hz}, \mathrm{H}-3^{\prime}\right), 3.02(1 \mathrm{H}, \mathrm{m}, \mathrm{H}-$ 13b), 2.07 (1H, m, H-2), 1.19 1.61 (21H, m, H-3 $\sim \mathrm{H}-8$, $\mathrm{H}-10 \sim \mathrm{H} 12, \mathrm{H}-15, \mathrm{H}-17), 1.24\left(3 \mathrm{H}, \mathrm{d}, J=6.5 \mathrm{~Hz}, \mathrm{H}-6^{\prime}\right)$, 0.87 and $0.85(6 \mathrm{H}$, overlapping triplets, $J=7.5 \mathrm{~Hz}, \mathrm{H}-16$, $\mathrm{H}-18) ;{ }^{13} \mathrm{C}-\mathrm{NMR}\left(\mathrm{CD}_{3} \mathrm{OD}, 125 \mathrm{MHz}\right) \delta 179.0(\mathrm{C}-1), 98.5$ $\left(\mathrm{C}-1^{\prime}\right), 78.7$ (C-9), $69.6\left(\mathrm{C}-4^{\prime}\right), 68.6\left(\mathrm{C}-2^{\prime}\right), 67.8$ (C-5'), 51.1 (C-2), 50.2 (C-3'), 42.3 (C-10), 39.7, 34.0, 28.5, 27.7, $27.6(\times 2), 27.2,26.4,26.1,22.1(\mathrm{C}-17), 19.8,16.8\left(\mathrm{C}-6^{\prime}\right)$, 12.4 (C-16), 9.2 (C-18); HRESIFT-MS $m / z 429.3312$ (calcd for $\mathrm{C}_{23} \mathrm{H}_{44} \mathrm{~N}_{2} \mathrm{O}_{5}+\mathrm{H}, 429.3330$ ).

\section{Biological Assays}

The in vitro assay against $H$. contortus was used as described in reference 2 . The in vivo mouse assay was modified from reference 3 and performed as follows: Swiss Webster mice (approx. $30 \mathrm{~g}$ ) were inoculated with 200 400 L3 $H$. polygyrus larvae. The mice were checked for infection around day 12 post inoculation, and then dosed intramuscularly with test compound in triplicate. On day three post treatment, mice were euthanized and the intestine was collected (from below stomach to above cecum), opened, and placed in five mls of sterile water. Mucosa was scraped and rinsed through a 200-mesh screen. The rinseate was then examined for presence of worms and worms were counted. Worm counts for treated mice were then compared to infected, untreated mice as negative controls, and infected mice treated with ivermectin $(10 \mathrm{mg} / \mathrm{kg})$ as positive controls.

\section{References}

1. McKellar QA, Jackson F. Veterinary anthelmintics: old and new. Trends in Parasitology 20: 456-461 (2004)
2. Michael B, Meinke PT, Shoop W. Comparison of ivermectin, doramectin, selamectin, and eleven intermediates in a nematode larval development assay. J Parasitol 87: 692-696 (2001)

3) Fonseca-Salamanca F, Martinez-Grueiro MM, MartinezFernandez AR. Nematocidal activity of nitazoxanide in laboratory models. Parasitol Res 91: 321-324 (2003)

4) Hegde VR, Patel MG, Gullo VP, Ganguly AK, Sarre O, Puar MS, McPhail AT. Macrolactams - a new class of antifungal agents. J Am Chem Soc 112: 6403-6405 (1990)

5. Hegde VR, Patel MG, Gullo VP, Puar MS. SCH-38518 and SCH-39185-2 novel macrolactam antifungals. J Chem Soc Chem Commun 810-812 (1991)

6. Hegde V, Patel M, Horan A, Gullo V, Marquez J, Gunnarsson I, Gentile F, Loebenberg D, King A, Puar M, Pramanik B. Macrolactams: a novel class of antifungal antibiotics produced by Actinomadura spp. SCC 1776 and SCC 1777. J Antibiot 45: 624-632 (1992)

7. Cooper R, Truumees I, Yarborough R, Loebenberg D, Marquez J, Horan A, Patel M, Gullo V, Puar M, Pramanik B. Macrolactams: two novel homologous series of compounds produced by Actinomadura sp. SCC 1778. J Antibiot 45: 633-638 (1992)

8. Naruse N, Tenmyo O, Kawano K, Tomita K, Ohgusa N, Miyaki T, Konishi M, Oki T. Fluvirucins A1, A2, B1, B2, B3, B4 and B5, new antibiotics active against influenza A virus. I. Production, isolation, chemical properties and biological activities. J Antibiot 44: 733-740 (1991)

9. Naruse N, Tsuno T, Sawada Y, Konishi M, Oki T. Fluvirucins A1, A2, B1, B2, B3, B4 and B5, new antibiotics active against influenza A virus. II. Structure determination. J Antibiot 44: 741-755 (1991)

10. Naruse N, Konishi M, Oki T. Fluvirucins A1, A2, B1, B2, B3, B4 and B5, new antibiotics active against influenza A virus. III. The stereochemistry and absolute configuration of fluvirucin A1. J Antibiot 44: 756-761 (1991)

11. Zhang Z, Wang Y, Ruan J. Reclassification of Thermomonospora and Microtetraspora. Int J Syst Bacteriol 48: 411-422 (1998)

12. Ayers S, Zink DL, Mohn K, Powell JS, Brown CM, Murphy T, Grund A, Genilloud O, Thompson D, Singh SB. Anthelmintic macrolactams from Nonomuraea turkmeniaca MA7364. J Nat Prod 70: 1371-1373 (2007) 